\title{
Blood Donation and the Foot-in-the-Door Technique: A Limiting Case
}

\author{
Robert D. Foss \\ Department of Sociology and Anthropology \\ Western Carolina University
}

\author{
Carolyn B. Dempsey \\ University of Tennessee, Knoxville
}

\begin{abstract}
Three experiments testing the effectiveness of the foot-in-the-door technique for recruiting blood donors consistently failed to demonstrate that this procedure influences either verbal or behavioral compliance, suggesting that the generality of the foot-in-the-door phenomenon is limited. Experiment 1 attempted to demonstrate that an earlier failure of this technique was due to poor operationalization rather than to the magnitude of the critical request or to the invalidity of the phenomenon, but it failed to do so. Experiment 2, designed to more closely resemble other foot-in-the-door studies by using telephone contacts and an initial request for persons to answer questions, was conducted to examine other possible explanations for the two previous failures. This experiment also failed to show any foot-in-the-door effect. Experiment 3 was a conceptual replication of Experiment 2 but used personal contacts. One apparent foot-in-the-door effect emerged in this case, but it was more likely due to a factor other than the experimental treatment. It is concluded that although the foot-in-the-door procedure may indeed influence verbal compliance with requests for minimal forms of aid, it probably will not significantly affect people's willingness to comply with more substantial requests involving behaviors that are psychologically costly to perform.
\end{abstract}

A number of recent investigations of the effects of compliance with a small request on subsequent compliance with a more substantial request (the "foot-in-the-door" phenomenon) suggest the possibility of a direct and exciting application of social psychological

The authors wish to express their appreciation to Morris White of the Asheville Regional Blood Center of the American Red Cross and Thomas Brinson of the MEDIC organization for their cooperation and assistance on this project and to Gail Whisenant for assisting with data collection in Experiment 1. A special note of appreciation is also due Anthony Greenwald for his careful consideration and comments on an earlier version of this article.

Carolyn B. Dempsey is now at the Special Projects Office, Eastern Band of the Cherokee Indian.

A report of Experiment 1 was presented at the annual meeting of the Southeastern Psychological Association, Hollywood, Florida, May 1977.

Requests for reprints should be sent to Robert $D$. Foss, Department of Sociology and Anthropology, Western Carolina University, Cullowhee, North Carolina 28723. knowledge to practical matters. It has been shown repeatedly that persons who are induced to comply with a small request are much more likely to comply with a subsequent (critical) request of greater magnitude than would be the case if there had been no preliminary request (Cann, Sherman, \& Elkes, 1975; Freedman \& Fraser, 1966; Pliner, Hart, Kohl, \& Saari, 1974; Seligman, Bush, \& Kirsch, 1976; Snyder \& Cunningham, 1975). The apparent reason for this effect is that initial compliance alters a person's self-perception, and as a result, the person, seeing himself/herself as more of a helper than previously, is more likely to help a stranger when asked (Snyder \& Cunningham, 1975) or merely when the situation presents itself (Uranowitz, 1975).

One clear implication of these findings is that various service organizations such as the American Cancer Society, the American Heart Association, the American Red Cross ought to be able to make good use of this technique to 
induce compliance with their requests for aid in their respective tasks. In fact, Pliner et al. (1974) were able to nearly double the number of contributors to the Cancer Fund in a suburban neighborhood of Toronto, Canada, by using this technique. However, with this exception and one other, all studies of the foot-in-the-door phenomenon have used rather trivial requests, and a large number have employed a single research paradigm, which is to make requests over the telephone for persons to answer varying numbers of questions.

When the foot-in-the-door technique was used in a different and more realistic field setting in an attempt to increase blood donations, it failed (Cialdini \& Ascani, 1976). In that study, the second request was made immediately after the first, which may not have allowed time for a person's self-perception to be sufficiently altered by compliance with the initial request. However, Cann et al. (1975) have shown, albeit in the somewhat artificial telephone interview paradigm, that timing of the second request apparently is not crucial for the foot-in-the-door effect to emerge. Therefore, it may simply be that moving from a rather trivial request such as answering questions in a telephone interview or donating money to a charity ${ }^{1}$ to a more substantial one such as asking for a blood donation provides more of an obstacle than the foot-in-thedoor technique can overcome.

Given that several studies of helping have documented a substantial rate of attrition between volunteering to do something and actually doing it (cf. Gross, Wallston, \& Piliavin, 1975; Kazdin \& Bryan, 1971), the generalizability of the foot-in-the-door phenomenon to settings in which such a technique might have some practical utility is further questioned; only Pliner et al. (1974) and Cialdini and Ascani (1976) have studied actual behavioral compliance with the critical request.

The present studies were designed to clarify some issues that are of importance for the practical application of the foot-in-the-door phenomenon. In particular, it would be useful to know (a) whether the effect does reliably occur with respect to overt behavior as well as verbal behavior, (b) whether the ef- fect extends to other than question-answering behavior, and (c) how strong the effect is. Since Cialdini and Ascani's (1976) negative results amount to an acceptance of the null hypothesis, a replication of this result would be desirable before much confidence is placed in it. Therefore, the present series of experiments also used the foot-in-the-door technique in an attempt to increase blood donations during the visit of a bloodmobile to a university campus. Experiment 1 is a modified replication of Cialdini and Ascani's experiment in which timing of the critical request was manipulated to see whether it was the timing or the magnitude of the critical request that was more likely responsible for the failure of the foot-in-the-door effect to materialize in that study.

\section{Experiment 1}

\section{Method}

Research participants were 76 dormitory residents at a small, rural university. For each hall in each of the 10 dormitories on campus, a room number was randomly selected. Two female experimenters individually approached selected rooms between 6 p.m. and 10 p.m. and made the following initial request to the person answering the door:

\section{$\mathrm{Hi}$, my name is and I am working as a volunteer for the Red Cross. Our bloodmobile is to be here next week [on Tuesday] [tomorrow] and Wednesday from 12:00 to 6:00 p.m. Would you help us advertise its visit by putting this poster on your door?}

Persons who agreed were given a poster that stated the time, place, and date of the bloodmobile visit and that contained the American Red Cross logo. The experimenter then took the subject's name and recorded his/her sex. All persons were thanked for their help, or if they did not cooperate, they were thanked just for listening. If no one answered the door of a preselected room, another room on the same hall was randomly selected and approached.

Timing between initial and critical requests was manipulated by making the initial request on the Wednesday (5-day delay) or Friday (3-day delay) of the week preceding the bloodmobile visit or on

\footnotetext{
1 Forty-eight percent donated with no prior request in the Pliner, Hart, Kohl, and Saari (1974) study, indicating that donating small amounts of money $(M<\$ 1)$ to a good cause is a behavior people are not terribly hesitant to engage in.
} 
Table 1

Percentage of Verbal and Behavioral Compliance by

Experimental Condition-Experiment 1

\begin{tabular}{ccccccccc}
\hline & \multicolumn{9}{c}{ Condition $(\%)$} & & \\
\cline { 2 - 5 } \multicolumn{1}{c}{ Compliance } & 5 -day delay & 3-day delay & No delay & Control & & $\chi^{2}$ & $p$ \\
\hline $\begin{array}{c}\text { Verbal compliance } \\
\text { Recontacted sample }\end{array}$ & $53(9$ of 17$)$ & $54(7$ of 13$)$ & $55(11$ of 20$)$ & $53(10$ of 19$)$ & .046 & $>.80$ \\
$\begin{array}{c}\text { Behavioral compliance } \\
\text { Recontacted sample }\end{array}$ & $18(3$ of 17$)$ & $38(5$ of 13$)$ & 25 & $(5$ of 20$)$ & 26 & $(5$ of 19$)$ & 1.672 & $>.50$ \\
Entire sample & $14(3$ of 22$)$ & $33(5$ of 15$)$ & 25 & $(5$ of 20$)$ & 26 & $(5$ of 19$)$ & 2.095 & $>.50$ \\
\hline
\end{tabular}

Note. $N$ s are given in parentheses. Data for verbal compliance are for 69 persons who were successfully contacted for both the initial and critical request (recontacted sample). Data for behavioral compliance are reported for these persons (recontacted sample) and for these persons plus 7 persons who could not be contacted for the critical request but whose behavioral compliance could nevertheless be determined (entire sample).

the Monday evening (no delay) prior to the bloodmobile visit. The critical request was then made on the Monday evening preceding the bloodmobile visit.

In the 5-day and 3-day delay conditions, persons were recontacted by a different experimenter who also presented herself as a Red Cross volunteer and asked if the person would be willing to donate a pint of blood.

In the no-delay condition, after the person had agreed to the initial request to display the poster, the experimenter continued with the following request: "There is one other thing you can do for us. We are asking students to donate one pint of blood tomorrow and I wondered if you would volunteer to donate?" In the control condition, persons were simply contacted for the first time on the Monday evening preceding the bloodmobile visit and asked if they would donate. A list of the names of all persons who appeared at the donation center and either donated or were deferred for medical reasons was obtained from the American Red Cross. This list was used to determine how many persons in each experimental condition actually complied behaviorally with the critical request as well as how many of those in each condition were previous blood donors.

\section{Results}

There were no sex differences for verbal compliance, with $55 \%$ of males (18 of 33 ) and $53 \%$ of females ( 19 of 36 ) verbally agreeing to donate nor were there any differences for behavioral compliance, with $27 \%$ of males ( 9 of 33 ) and $25 \%$ of females ( 9 of 36) actually appearing at the donation center. ${ }^{2}$ Therefore, male and female data were combined for the following analyses.

Verbal compliance. Table 1 indicates that there was practically no variation in compliance across conditions, and the differences did not approach statistical significance, $\chi^{2}(3)<1$. Combining all experimental conditions, the overall verbal compliance was $54 \%$ ( 27 of 50 ), which is virtually identical to the $53 \%$ compliance rate in the control condition, $\chi^{2}(1)<1$.

Behavioral compliance. It was expected that behavioral compliance would be substantially less than verbal compliance, and this turned out to be the case (see Table 1), with only about half of those who verbally complied actually showing up to donate. Again, there were no significant differences in compliance rates between conditions, $\chi^{2}(3)=$ $1.67, p>.50$. The compliance rate in the combined experimental conditions was $26 \%$ (13 of 50), which is identical to the compliance rate in the control condition.

In an attempt to determine why behavioral compliance was so much lower than verbal compliance, information about the previous donation history of all persons who verbally complied was obtained from local Red Cross records. As Table 2 indicates, this one bit of information is vital in explaining differences in behavioral compliance among those who verbally complied. Of those who had donated

2 Seven persons could not be recontacted for the critical request (five in the 5-day delay condition and two in the 3-day delay condition). 
before, $82 \%$ ( 14 of 17 ) carried through on their verbal commitment, whereas only $21 \%$ (4 of 19) of those who had never donated before did so, $\chi^{2}(1)=11.15, p<.001 \quad(\phi=$ $.61) .^{3}$ Thirty-seven percent of the variation in behavioral compliance in this group was accounted for by donation history. Furthermore, it is evident from the table that this relationship between donation history and behavioral compliance holds up within both the experimental condition, $\chi^{2}(1)=7.96, p<.005(\phi$ $=.63$ ) and the control condition (Fisher's exact test, $p=.083, \phi=.65$ ), suggesting that the experimental treatment had no effect on the relationship between these variables.

\section{Discussion}

The present results call into question the external validity of the foot-in-the-door phenomenon. While it previously appeared that Cialdini and Ascani (1976) may not have obtained the usual effect because of an improper operationalization of the technique, the present study rules out this interpretation and leaves us with the suspicion that this phenomenon may not be robust enough to affect those behaviors that people are initially somewhat hesitant to engage in. It is wellknown that most people, if they have never donated blood before, are quite reluctant to do so (American Red Cross, undated). On the other hand, examining the amount of compliance obtained in control conditions of previous foot-in-the-door studies, we find that anywhere from $17 \%$ (Freedman \& Fraser, 1966) to 50\% (Cann et al., 1975) of the people who were simply asked initially to engage in the criterion behavior were willing to do so. This suggests that none of these behaviors were particularly noxious in the first place. (Indeed, with the exception of the Freedman \& Fraser experiments, the criterion behaviors were quite minimally inconveniencing or costly.) ${ }^{4}$

Another possible reason for the failure of the foot-in-the-door effect to materialize for Cialdini and Ascani (1976) as well as in the present experiment has to do with situational factors that may have intervened to prevent any alteration in self-perception as a result
Table 2

Behavioral Compliance of Previous Donors and Previous Nondonors-Experiment 1

\begin{tabular}{|c|c|c|c|c|}
\hline \multirow[b]{3}{*}{ Compliance } & \multicolumn{4}{|c|}{ Condition } \\
\hline & \multicolumn{2}{|c|}{ Experimental ${ }^{\mathbf{a}}$} & \multicolumn{2}{|c|}{ Control $^{\mathbf{b}}$} \\
\hline & Donor & $\begin{array}{l}\text { Non- } \\
\text { donor }\end{array}$ & Donor & $\begin{array}{l}\text { Non- } \\
\text { donor }\end{array}$ \\
\hline $\begin{array}{l}\text { Yes } \\
\text { No }\end{array}$ & $\begin{array}{l}9 \\
1\end{array}$ & $\begin{array}{r}4 \\
12\end{array}$ & $\begin{array}{l}5 \\
2\end{array}$ & $\begin{array}{l}0 \\
3\end{array}$ \\
\hline Total & 10 & 16 & 7 & 3 \\
\hline
\end{tabular}

Note. This table includes only those persons who verbally complied with the request to donate blood plus two who failed to verbally comply but donated anyway.

a In the experimental condition, $\chi^{2}(1)=7.96, p$ $<.005, \phi=.63$.

b In the control condition, Fisher exact, $p=.083$, $\phi=.65$.

of compliance with the initial request. If there is strong external justification for a behavior, that behavior is likely to be dis-

\footnotetext{
${ }^{3}$ All chi-square values reported with 1 degree of freedom are corrected for continuity.

${ }^{4}$ It might be argued that the $32 \%$ verbal compliance rate obtained by Cialdini and Ascani (1976) and the $53 \%$ verbal compliance in the present study provide evidence that people are also fairly willing to donate blood; however, such a conclusion is not justified. The baseline compliance rate in blood donation studies is elevated by the presence in the sample of previous donors, who are much more likely to agree to give blood than persons who have never donated (Foss, Note 1). Consequently, this baseline rate is not an accurate indicator of the reluctance of people in general to engage in this particular criterion behavior.

In the present study, both the $53 \%$ verbal compliance and the $26 \%$ behavioral compliance are abnormally high and, in fact, are much higher than those reported by Cialdini and Ascani (1976). This can be accounted for the fact that there is a wellorganized, continuing effort to obtain blood donations on the campus at which the present study was conducted, providing a climate of normative support for this activity (cf. Barton, 1969), and many students have donated previously. Indeed, of those in the present experiment who verbally complied, $47 \%$ were previous donors, and $78 \%$ of those who actually donated were previous donors. In a subsequent study (Experiment 2) conducted on another campus at which the normative climate is not so conducive to blood donation, verbal compliance was only $25 \%$ and behavioral compliance a mere $3 \%$.
} 
counted rather than taken as an indication of a person's character (Bem, 1972; Kelley, 1971). It is quite possible that the initial request (to help advertise the presence of a mobile blood-collection unit on campus) was for such a good cause that people perceived a great deal of external justification for doing so- "Sure I'll do that, anybody would."and, hence, did not attribute "helper" characteristics to themselves subsequent to the initial behavior.

There is yet another possible explanation for the failure of the foot-in-the-door technique to influence blood donation. It may be that size of the initial and critical requests must be correlated such that for a larger critical request, one must use a more substantial initial request. Seligman et al. (1976) found this to be the case using the telephone interview paradigm, and it is plausible that one's self-perception will be more strongly influenced by an initial agreement to a moderate request than to a small request. Therefore, it may still be possible to develop practical applications of this technique in areas in which human aid or assistance are needed but in which people are reluctant to provide such services. However, by having to increase the magnitude of the initial request, one is of necessity decreasing the number of persons who can be subjected to the technique, because of the decreased likelihood of compliance with the initial request. One of the main appeals of the foot-in-the-door technique is the possibility that even the most trivial of initial requests may be sufficient to increase subsequent compliance. However, if this is not the case, and considering the substantial effort that would be necessary to carry out a recruitment project using this technique, the minimal payoffs may not be worth the effort. Nevertheless, in the interest of a better understanding of this phenomenon and to provide a more thorough specification of relevant parameters, two further experiments were conducted.

\section{Experiment 2}

A second study was conducted to examine the possibilities suggested earlier (a) that be- cause of the compelling nature of the request used, altered self-perceptions might not be induced or (b) that the initial request was not large enough to alter self-perceptions sufficiently to influence compliance with so large a request as donating blood. Contacts were made by telephone, as has been the case in most other foot-in-the-door studies, and a condition similar to that typically used in such studies was added to approximate more closely the procedures used in studies in which this technique has been successful. This experiment was also conducted in connection with a 2 -day bloodmobile visit to a university campus.

\section{Method}

Research participants were 135 dormitory residents at a large, urban university. Participants were randomly selected from a listing of dormitory residents and assigned to one of three experimental conditions or to a control group. Persons in the experimental conditions were then contacted by phone on either Wednesday or Thursday evening between 6:00 p.m. and 9:30 p.m. and were asked if they would be willing to do one of the following tasks, depending on the condition to which they had been assigned:

Routine initial request. Subjects were asked to answer a few questions about blood donation. If they agreed, five questions were asked, including whether they had ever donated, and they were thanked for their cooperation.

Poster request. Subjects were asked to allow the blood organization to put a poster on their dormitory room door to advertise the bloodmobile visits. If they agreed, they were asked the location of their room, their age, and whether they had ever donated blood. They were then thanked for their cooperation.

Large initial request. Subjects were asked to recruit four friends to donate blood as part of a new approach to donor recruitment being tried during the upcoming bloodmobile visit. If they agreed, they were simply told to contact four friends, inform them that the bloodmobile would be on campus the following Monday and Tuesday, and ask them to donate. Participants were then asked their age and whether they personally had ever donated. They were then thanked for their cooperation.

On the following Sunday and Monday nights (3-5 days later), all experimental subjects and all members of the control group were called by a different person, who informed them that the bloodmobile would be on campus for two days and who asked them if they would be willing to donate a unit of 
Table 3

Percentage of Verbal and Behavioral Compliance by

Experimental Condition-Experiment 2

\begin{tabular}{|c|c|c|c|c|c|c|}
\hline \multirow[b]{2}{*}{ Item } & \multicolumn{4}{|c|}{ Condition $(\%)$} & \multirow[b]{2}{*}{$x^{2}$} & \multirow[b]{2}{*}{$p$} \\
\hline & $\begin{array}{c}\text { Routine } \\
\text { request }\end{array}$ & $\begin{array}{l}\text { Poster } \\
\text { request }\end{array}$ & $\begin{array}{l}\text { Large } \\
\text { request }\end{array}$ & Control & & \\
\hline \multicolumn{7}{|l|}{ Verbal compliance } \\
\hline Recontacted sample & $20(6$ of 30$)$ & $29(6$ of 21$)$ & $31(9$ of 29$)$ & $20(6$ of 30$)$ & 1.51 & $>.60$ \\
\hline Previous nondonors & $19(5$ of 26$)$ & $22(4$ of 18$)$ & 33 (9 of 27$)$ & $22(5$ of 23$)$ & 1.67 & $>.60$ \\
\hline \multicolumn{7}{|l|}{ Behavioral compliance } \\
\hline Entire sample & $5(2$ of 41$)$ & $4(1$ of 28$)$ & $0(0$ of 36$)$ & $3(1$ of 30$)$ & - & 一 \\
\hline
\end{tabular}

Note. Ns are given in parentheses. Data for verbal compliance are for 110 persons who were successfully contacted for both the initial and critical request. Data for behavioral compliance are for these persons plus 25 others who could not be contacted for the critical request but whose behavioral compliance could nevertheless be determined (one of the donors in the routine condition was in this group).

blood. ${ }^{5}$ Persons who agreed were told of the time and place and were reminded to eat a good meal before coming to donate.

To summarize, there were three experimental conditions ranging from a small initial request, which is the type normally used in foot-in-the-door research, to a moderate initial request that was essentially identical to that used in Experiment 1, to a large initial request that should have a greater effect on self-perceptions if persons agree to it. There was also a control condition with no initial request.

\section{Results}

Verbal compliance. Twenty-five persons could not be recontacted for the critical request ( 7 each in the poster and large request conditions, 11 in the routine condition), hence, for these people the amount of verbal compliance is unknown. ${ }^{6}$ Persons who said they might donate were classified as refusals. Table 3 shows the amount of verbal compliance both before and after persons who reported they were previous donors were removed from the analysis. In neither case was the overall chi-square significant. In both instances the greatest amount of verbal compliance was obtained in the large initial request condition, but in neither case was this significantly different from the control condition. Finally, combining the experimental groups, the overall compliance rate was $26 \%$ ( 21 of 80 ), which does not differ from the $20 \%$ compliance obtained in the control condition, $\chi^{2}(1)<1$. With previous donors removed, the combined compliance rate was
$25 \%$ (18 of 71 ), which is not significantly different from the $22 \%$ compliance in the control condition, $\chi^{2}(1)<1$.

Behavioral compliance. There was virtually no behavioral compliance, with only four persons donating, one of whom had not been successfully contacted for the critical request. This result underscores one conclusion of another study of blood donation that personal contact is a far more effective recruitment technique than telephone contact (Ford \& Wallace, 1975). Unfortunately, the extremely small amount of behavioral compliance obtained in the present study $(3 \%)$ precludes a definitive test of the possible effects of differing initial requests, although the failure of effects to materialize with verbal com-

5 All callers were unaware of the hypothesis being tested. Although some persons in the large request condition may have failed to behaviorally comply with the initial request, only 2 persons (poster condition) would not agree to the initial request. Due to the time pressures generated by having to contact 135 persons within two fixed $3 \frac{1}{2}$-hour time periods, these 2 persons were not recontacted for the critical request but were included in the analyses where possible (i.e., behavioral compliance).

${ }^{6}$ This is a disturbingly large attrition rate; however, there is little reason to believe that these persons differ in any important way from those we could successfully recontact. Because of the logistics of contacting a large number of persons during a relatively short time period, only a limited number of call backs were possible, and these persons simply were not in when we called. 
pliance suggests once again that the foot-inthe-door technique simply does not work with blood donation. Nevertheless, a third experiment was conducted in a further attempt to determine if it might yet work under the right circumstances.

\section{Experiment 3}

\section{Method}

This experiment was conducted on the same campus as Experiment 1, 9 months later, during a different academic year, and again in connection with a bloodmobile visit to campus. Procedures were similar to those in Experiment 2, but dormitory rooms rather than individuals were sampled to maximize the sample size with which we would ultimately be able to make two contacts. Five or 6 days prior to the bloodmobile visit, research participants were contacted in person by an experimenter who delivered one of three initial requests to whomever answered the door, depending on the condition to which the room had been assigned:

Routine initial request. Subjects were asked to answer six or seven questions about their knowledge of and experience with blood donation.

Poster request. Subjects were asked to put a poster on their door advertising the bloodmobile visit to campus.

Large initial request. Subjects were asked to recruit four of their friends to donate blood.

Persons who agreed to the request were asked the questions, given the poster, or told how to recruit friends as in Experiment 2. They were then asked their names and whether they had ever donated blood. For purposes of secondary analysis, a record was kept of all persons who reported conditions that would legitimately disqualify them from donating blood (chronic illness, underweight, temporary illness, etc.).

On the evening preceding the bloodmobile visit, all persons who had received an initial request and persons in the control group were contacted by a different experimenter (who feigned ignorance of the earlier contact by an experimenter) 7 and asked to donate blood the following day. Those who agreed to donate were reminded of the time and place and to eat a good meal before coming to donate. Everyone was thanked for his/her time, even if he/she had refused to donate.

\section{Results}

Of the 127 persons initially contacted, 95 were successfully recontacted and asked to donate blood. In addition, 36 persons in the control group were contacted for the first time and asked to donate. Since there were no significant differences between males and females for verbal compliance ( $36 \%$ vs. $39 \%$ ) or for behavioral compliance ( $12 \%$ vs. $14 \%$ ), data were combined for the following analyses. $^{8}$

Verbal compliance. Although there were some moderate variations in verbal compliance across conditions (see Table 4), these did not approach statistical significance, $\chi^{2}(3)$ $=2.30, p>.50$. Compliance was greatest in the poster condition (44\%), although it did not differ significantly from the control condition, $\chi^{2}(1)=1.27, p>.20$. The $40 \% \quad(38$ of 95) compliance rate among combined experimental conditions also did not differ significantly from the control condition, $\chi^{2}(1)$ $<1$.

Behavioral compliance. Since 32 persons could not be recontacted for the critical request $(8,11$, and 13 in the routine, poster, and large request conditions, respectively), two sets of analyses were conducted. Although these persons were not directly asked to donate, they were in experimental conditions that, in view of the processes apparently involved in the foot-in-the-door phenomenon, should have made them more likely to do so when the opportunity presented itself (cf. Uranowitz, 1975). On the campus at which this study was conducted, almost everyone knows when the bloodmobile is on campus and, therefore, is aware of the opportunity to donate.

First, in the recontacted sample (see Table 4 ), which provides the easier task for the foot-

7 Both verbal and behavioral compliance rates were substantially higher in Experiment 1. This finding appears to have been due primarily to the fact that Experiment 3 was conducted during the winter, in the midst of a flu epidemic, whereas Experiment 1 was conducted in the spring.

${ }^{8}$ Although recruiters were initially blind to the respondent's experimental condition, those in the poster condition were easily recognized as such when the recruiter approached the room. This is unfortunate but is probably not serious, since recruiters were unaware of the specific nature of the hypotheses being tested. Furthermore, the crucial question became (see below) whether any or all experimental conditions differed from the control group rather than whether there were any differences between experimental conditions. 
Table 4

Percentage of Verbal and Behavioral Compliance by Experimental Condition-Experiment 3

\begin{tabular}{|c|c|c|c|c|c|c|}
\hline \multirow[b]{2}{*}{ Item } & \multicolumn{4}{|c|}{ Condition $(\%)$} & \multirow[b]{2}{*}{$x^{2}$} & \multirow[b]{2}{*}{$p$} \\
\hline & $\begin{array}{l}\text { Routine } \\
\text { request }\end{array}$ & $\begin{array}{l}\text { Poster } \\
\text { request }\end{array}$ & $\begin{array}{l}\text { Large } \\
\text { request }\end{array}$ & Control & & \\
\hline \multicolumn{7}{|l|}{ Verbal compliance } \\
\hline Recontacted sample & $43(16$ of 37$)$ & $44(14$ of 32$)$ & $31(8$ of 26$)$ & $31(11$ of 36$)$ & 2.30 & $>.50$ \\
\hline \multicolumn{7}{|l|}{ Behavioral compliance } \\
\hline Recontacted sample & $16(6$ of 37$)$ & $31(10$ of 32$)$ & $12(3$ of 26$)$ & $6 \quad(2$ of 36$)$ & 8.83 & $<.05$ \\
\hline Entire sample & $13(6$ of 45$)$ & $23(10$ of 43$)$ & $8(3$ of 39$)$ & $6 \quad(2$ of 36$)$ & 6.79 & $<.08$ \\
\hline
\end{tabular}

Note. $N$ s are given in parentheses. Data for the recontacted sample are for 131 persons who were successfully contacted for both the initial and critical request. Data for the entire sample also include 32 persons who could not be contacted for the critical request but whose behavioral compliance could nevertheless be determined.

in-the-door technique, there was a significant overall effect, $\chi^{2}(3)=8.83, p<.05$; this was accounted for by the poster condition, which differed significantly from the control condition, $\chi^{2}(1)=6.03, p<.02$. Neither of the other experimental conditions differed significantly from the control group. The combined experimental conditions differed from the control group at a marginal significance level $(20 \%$ vs. $6 \%), \chi^{2}(1)=3.05, p<.09$, but again this is due primarily to the contribution of the poster condition.

For the entire sample, behavioral compliance in the experimental conditions was again somewhat higher than in the control condition, and the overall effect approached conventional levels of statistical significance, $\chi^{2}(3)=6.79, p<.08$. The poster condition accounted for this effect and was significantly different from the control condition $(23 \%$ vs, $6 \%), x^{2}(1)=3.49, p<.06$, whereas neither of the other two experimental conditions differed significantly from the control group. It should be pointed out that none of the 32 persons who were not recontacted actually donated, and it is arguable that the only fair test of the foot-in-the-door effect is the previous one involving only those contacted for both the initial and critical requests.

Donation history. Among those persons who reported having donated previously, 59\% (23 of 39) agreed to donate and among those who had not donated previously $30 \%$ (25 of
83) agreed to donate; $\chi^{2}(1)=8.09, p<.01 .^{10}$ Actual donation was also more common among previous donors $(24 \%, 13$ of 54$)$ than among persons who had never donated $(8 \%, 8$ of 100), $\chi^{2}(1)=6.39, p<.02$.

In the present experiment, previous donation history did not play such a strong role in determining whether persons who agreed to donate would actually do so as it did in Experiment 1. Nearly half $(48 \%)$ of those who agreed to donate were previous donors, and of those, $39 \%$ actually donated, whereas $28 \%$ of those who agreed to donate but were not previous donors actually did so, $\chi^{2}(1)$ $<1$. Still, donation history is an important determinant of behavioral compliance, with those who have donated before three times as likely to donate as those who have not previously done so. ${ }^{11}$ In the present experiment,

9 A third set of analyses was conducted after excluding the 44 persons who reported a legitimate medical excuse for not donating, as well as the 32 persons not recontacted. This altered the percentages, but the same pattern of results as in the above analyses emerged for both verbal and behavioral compliance.

10 Because of an oversight, information about donation history was not obtained from nine persons in the control group.

11 In this study, information on donation history was obtained from the persons themselves, whereas in Experiment 1, it was obtained from actual records. It is possible that some persons felt a need to deceive us about their donation history and, therefore, that the results of this analysis are less reliable than those from Experiment 1. 
previous donors constituted only one third $(35 \%)$ of the sample, yet nearly two thirds (62\%) of the donations were made by persons who had previously donated.

\section{General Discussion}

Since the experiments reported here primarily provide confirmation of a null hypothesis, a brief discussion of methodological issues surrounding this procedure is in order. Traditionally, in social psychology, experimental results that confirm the null hypothesis have been viewed with more than a little skepticism-often with good reason (Aronson \& Carlsmith, 1968). Even if a study is well designed and well executed, one plausible alternative explanation of experimental results that confirm a null hypothesis is that the statistical test used may not have been powerful enough to detect a true effect. Thus, conventional canons of research dictate that very large samples are necessary to effectively test a null hypothesis.

The samples in the present study clearly are not particularly large, averaging about 31 persons per condition, which leaves open the possibility that the foot-in-the-door technique does indeed have an effect on compliance with requests to donate blood, but the effect is too small to detect with such small sample sizes. However, the purpose of the present studies was not the traditional one of examining a theoretical proposition but rather to examine the utility of a phenomenon in practical application. In such a situation, we are not particularly interested in small effects, real though they may be. Even though a compliance-inducing procedure might have the (statistically reliable) effect of increasing compliance by, say, $25 \%$ over normal procedures (an effect that would not be detected with a moderate sample size), this might very well be too small an effect to be of value in practical applications. ${ }^{12}$ In organizational donor recruitment programs, cost-benefit analyses must be conducted, and on balance, procedures that produce real but small effects are not feasible unless they involve essentially no extra effort or expense to put into practice. To this we would add that in the present series of experiments, there is little evidence to suggest that there is even a small foot-in-the-door effect that would have been detected with larger sample sizes. The fluctuation in compliance rates across experiments and conditions appears to be essentially random.

In the three experiments conducted, comprising a total of nine experimental groups evaluated on two dependent measures each, only one foot-in-the-door effect occurred (Experiment 3 , poster condition, behavioral compliance). The fact that this effect occurred in a condition that had no discernible effect in several other comparisons in Experiments 1 and 2 and that a behavioral compliance effect occurred in a condition in which there was no verbal compliance effect was somewhat puzzling. Further examination of the data yielded an explanation for this result. It was discovered that this one condition contained a substantially larger proportion of previous donors than any other condition $(47 \%$ vs. $28 \%, 29 \%$, and $37 \%$ in the routine, large request, and control conditions, respectively). Given the much stronger inclination of previous donors to donate, this provides a more parsimonious explanation of the greater behavioral compliance in this condition than does the foot-in-the-door explanation.

Given the consistent failure across three experiments to find a foot-in-the-door effect, despite different procedures (both telephone and in-person requests), study of different populations (urban and rural universities), and testing some of the most plausible alternative explanations for the initial failure, the only reasonable conclusion we are left with is that the foot-in-the-door technique does not work with blood donation. It appears that this behavior is too costly for a slightly altered self-concept, which the foot-in-the-door procedure presumably produces, to influence a person's willingness to donate.

\footnotetext{
12 Assuming a $12 \%$ rate of compliance with a straightforward request to donate blood (based on control groups of studies in which persons were personally asked), a $25 \%$ increase above that would amount to only $3 \%$ more donors, which would hardly justify the expense of doubling the number of personal contacts in order to bring about the foot-inthe-door effect.
} 
The present series of experiments provides evidence that the power of the foot-in-thedoor technique for practical applications may have been overstated. Two of the most comprehensive and popular recent social psychology textbooks maintain that the effectiveness of this technique is well established (Baron \& Byrne, 1977; Wrightsman, 1977). However, although the existence of the foot-inthe-door phenomenon is well documented, its utility in practical applications is not, with only a single study demonstrating an effect on behavioral compliance with a request for a meaningful form of aid. The present series of failures, in addition to at least two others (Cann, 1975; Cialdini \& Ascani, 1976), combined with the shortcomings of other studies previously mentioned, suggest that this technique may be of only limited value to organizations seeking ways to increase compliance with their requests for aid.

We suggest that at least part of the reason that the misconception about the power and practical usefulness of this technique has developed is because of the characteristics of the research publication system, which discourage the submission and acceptance for publication of studies that report negative results, that is, those studies that support the null hypothesis (Greenwald, 1975). Such biases against accepting the null hypothesis are particularly serious when results of social psychological inquiry are likely to be rapidly applied. If only positive findings emerge, a very misleading conception of a phenomenon can develop, and this appears to be precisely what has occurred with the footin-the-door phenomenon. The technique does appear to work well in some fairly limited instances, but the limitations have not been spelled out. The present series of experiments is a first step in the direction of identifying the crucial parameters that influence if, when, and perhaps how this technique works. Clearly, much remains to be done in order that future reports on the foot-in-the-door technique can be accompanied by appropriate cautionary remarks detailing the limitations of this procedure.

One final point is worth mentioning. Although the present series of experiments demonstrates convincingly that the foot-in-the- door effect does not influence blood donation, some caution should be exerted in interpreting these findings. On the basis of this single series of experiments plus one other (Cialdini \& Ascani, 1976), it would be risky to conclude that all costly behaviors are resistant to the foot-in-the-door phenomenon, although the implication is certainly there. In some ways, blood donation is perhaps an unusual form of helping. For example, previous donation is an extremely powerful factor in present behavior, which is primarily a reflection of the irrational fears people have about donating blood (cf. Foss, Note 1). On the other hand, it would be equally unwise to attempt to explain away the present results as being due to the peculiar nature of blood donation. Other behaviors such as donation of organs, bone marrow, and large amounts of time or money have equally high costs (of varying sorts) and are also behaviors that a given proportion of any population simply cannot engage in because of physical or other unalterable limitations. Finally, if blood donation were also resistant to other, thoroughly documented, forms of social influence, we would be justified in concluding that the current results tell us more about blood donation than about the foot-in-the-door phenomenon. However, blood donation is quite susceptible to various other forms of social influence (cf. Cialdini \& Ascani, 1976; Condie, Warner, \& Gillman, 1976; Ford \& Wallace, 1975; Foss, Note 1). Therefore, we may conclude with some confidence that the peculiar nature of blood donation alone does not explain our consistent negative findings.

\section{Reference Note}

1. Foss, R. D. The role of social infuence in blood donation. Paper presented at annual meeting of American Psychological Association, Toronto, August 1978.

\section{References}

American National Red Cross. Selected readings in donor motivation and recruitment. Washington, D.C.: Author, undated.

Aronson, E., \& Carlsmith, J. M. Experimentation in social psychology. In G. Lindzey \& E. Aronson (Eds.), Handbook of social psychology (Vol. 2, 2nd ed.). Reading, Mass.: Addison-Wesley, 1968. 
Baron, R. A., \& Byrne, D. Social psychology: Understanding human interaction. Boston: Allyn \& Bacon, 1977.

Barton, A. H. Communities in disaster. New York: Doubleday, 1969.

Bem, D. J. Self-perception theory. In L. Berkowitz (Ed.), Advances in experimental social psychology (Vol. 6). New York: Academic Press, 1972.

Cann, A. A. The effects of performing a small consonant behavior on subsequent attitudes and behaviors. (Doctoral dissertation, Indiana University, 1975). Dissertation Abstracts International, 1976, 36, 5859.B. (University Microfilms No. 7611, 359)

Cann, A. A., Sherman, S. J., \& Elkes, R. Effects of initial request size and timing of second request on compliance: The foot in the door and the door in the face. Journal of Personality and Social Psychology, 1975, 32, 774-882.

Cialdini, R. B., \& Ascani, K. Test of a concession procedure for inducing verbal, behavioral and further compliance with a request to give blood. Journal of Applied Psychology, 1976, 61, 295-300.

Condie, S. J., Warner, W. K., \& Gillman, D. C. Getting blood from collective turnips: Volunteer donation in mass blood drives. Journal of Applied Psychology, 1976, 61, 290-294.

Ford, G. T., \& Wallace, E. L. Effects of donor recruitment methods on population responses. Transfusion, 1975, 15, 159-164.

Freedman, J. L., \& Fraser, S. C. Compliance without pressure: The foot-in-the-door technique. Journal of Personality and Social Psychology, 1966, 4, 195-202.
Greenwald, A. G. Consequences of prejudice against the null hypothesis. Psychological Bulletin, 1975, $82,1-20$.

Gross, A. E., Wallston, B. S., \& Piliavin, I. M. Beneficiary attractiveness and cost as determinants of responses to routine requests for help. Sociometry, 1975, 38, 131-140.

Kazdin, A. E., \& Bryan, J. H. Competence and volunteering. Journal of Experimental Social Psychology, 1971, 7, 87-97.

Kelley, H. H. Attribution in social interaction. Morristown, N.J.: General Learning Press, 1971.

Pliner, P., Hart, H., Kohl, J., \& Saari, D. Compliance without pressure: Some further data on the foot-in-the-door technique. Journal of Experimental Social Psychology, 1974, 10, 17-22.

Seligman, C., Bush, M., \& Kirsch, K. Relationship between compliance in the foot-in-the-door paradigm and size of first request. Journal of Personality and Social Psychology, 1976, 33, 517-520.

Snyder, M., \& Cunningham, M. R. To comply or not comply: Testing the self-perception explanation of the foot-in-the-door phenomenon. Journal of Persomality and Social Psychology, 1975, 31, 64-67.

Uranowitz, S. W. Helping and self-attributions: A field experiment. Journal. of Personality and Social Psychology, 1975, 31, 852-854.

Wrightsman, L. Social Psychology (2nd ed.). Monterey, Calif.: Brooks/Cole, 1977.

Received April 21, 1978 